\title{
Safety Report Confidentiality Code
}

National Cancer Institute

\section{Source}

National Cancer Institute. Safety Report Confidentiality Code. NCI Thesaurus. Code C95392.

A coded value specifying privacy requirements for information about the safety report. 